\title{
SOME HITHERTO UNDESCRIBED HABITS OF MESKEA DYSPTERARIA GROTF.
}

\author{
By Richard L. Schwartz, \\ University of Texas, Austin, Texas.
}

A number of lepidopterous galls were collected during the summer of 1923 in the stems of Abutilon incanum while the plants were still in foliage. When opened these galls were found to contain lepidopterous larvæ of the internal borer type, naked and spotted with brown. The gall chambers were entirely free of excrement, yet there was no apparent opening of the gall. Upon careful inspection, it was discovered that there were several minute holes scattered over the gall and through these holes the tiny pellets of excrement were thrust out by the moth larvæ after discharge. Since these early galls were immature, none of them were kept.

On February 8, 1924, about thirty galls were collected from the dry stalks of another species of mallow, Malvaviscus drummondii near Austin. From that date on during the winter and early spring more galls were obtained until the total number collected and examined reached sixty-three. In February when the first galls were gathered, photographs were taken of the galls and caterpillars. These are shown in the accompanying figures $(1 \mathrm{a} ; 1 \mathrm{~b})$ including one case in which three larvæ were so close together that the result was a single gall. All of the galls gathered were on the stems except a single one which was attached to a leaf petiole.

Galls were broken open from time to time to observe the time of pupation and the first pupæ were found on March 24 . In the galls collected in February, the caterpillars had eaten out all the tender pith of the stems, but the hard lignified outer wall of the stem was not penetrated. In all the galls which contained pupæ it was found that the larvæ had cut through the hard wall a small, round perforation large enough to allow the mature moth to emerge, but the paper-like outer membrane of the stem was intact. The sawdust accumulated by the boring of this hole was piled up in both ends of the gall, and in the upper end was also the last larval skin. The sealed aperture is undoubtedly a 


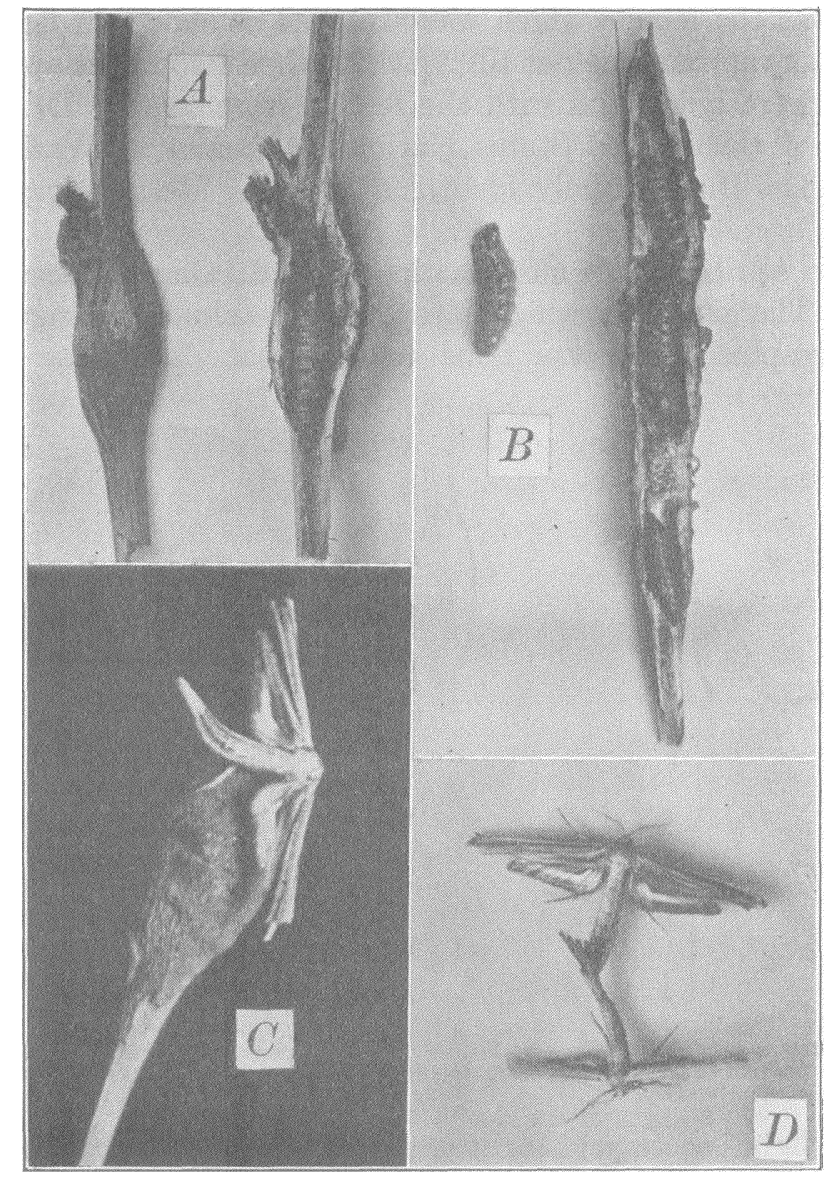

Fig. 1. Meskea dyspteraria Grote. $A$, galls; $B$, communal gall formed by three larvæ; $C$, 'moth resting on gall; $D$, moths in copula.

precaution which permits the easy emergence of the moth, and at the same time prevents the location of the place of emergence by parasites and enemies of the pupæ. The moths usually pupate upside down with the head placed directly in front of the future doorway through which the adult is to come out. The position of the pupæ in the gall is shown in figure $2 \mathrm{~b}$.

On the morning of March 15, 1924, the first moth emerged. 
This was the female which was sketched as shown in figure $2 a$. No other moths came out till April 20 when two males appeared. These were killed and with the female were sent to Dr. H. G. Dyar, of the United States National Museum at Washington where Dr. Busck kindly identified them as Meskea dyspteraria Grote.

On April 23 three more moths emerged. One of these, was a male. The gall from which it emerged is shown in figure 1a. Photographic work was done under great difficulties as the

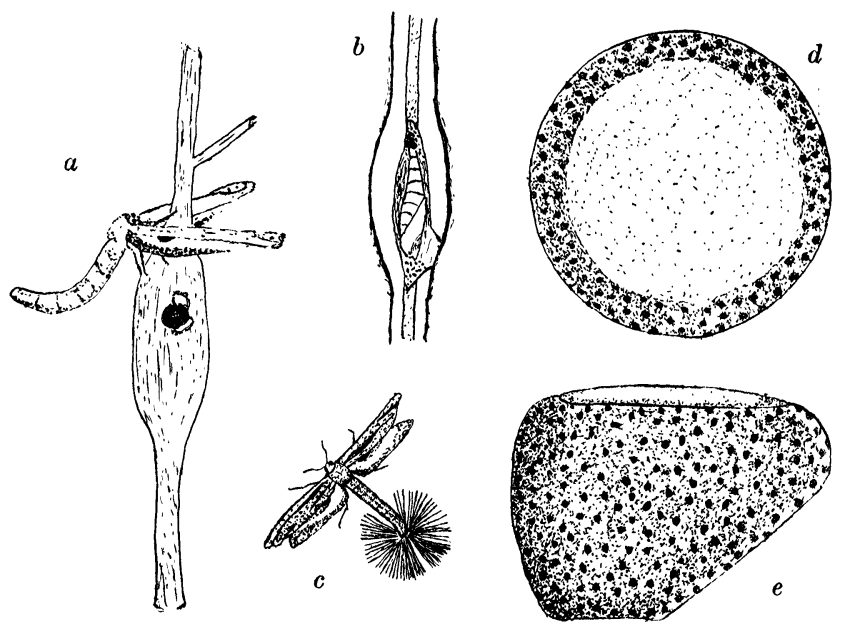

Fig. 2. Meskea dyspteraria Grote. $a$, Female moth resting on gall; $b$, section of gall showing position of pupa; $c$, male with copulatory tuft extended; $d$, egg seen from the top $e$, same from side.

strong light necessary for the camera disturbed the moths. This difficulty was later overcome in studying the moths at night by the use of a red light which did not seem to disturb them. After April 23 several moths emerged each warm night, although six was the greatest number of living moths under observation at any one time. On June 6, when the author left Austin, several of the moths had not yet appeared.

Some very interesting and hitherto unobserved details of the habits of the moths in mating were observed with the use of the red light mentioned above. Soon after darkness, the male moths extrude from the posterior tip of the abdomen an elongated 
tuft of hairs which we may call the copulatory tuft. After this tuft is extruded, it is spread out much in the manner in which a peacock or turkey spreads its tail. This spreading is dorsoventral as well as lateral, and the tuft is vibrated if the moth is disturbed. Though the presence of the female in the same breeding cage is not necessary to induce this behavior, there every indication that the tuft functions in mating. Unfortunately the author was not able to observe the moths at the moment in which the final stages of courtship took place and a more thorough study would probably bring out other details of interest. In this species the wings and body of the two sexes are identical in color pattern.

Attempts to photograph the copulatory tuft when spread were rather unsuccessful, as the moth usually vibrated the tuft when disturbed or retracted it entirely, and the feathery nature of the tuft makes it a hard object to photograph even when expanded. Its form is however shown in a sketch reproduced as Fig. 2c. Fig. 1d, is an excellent photograph of the contracted position of the tuft in copulation. The tuft is drawn into the abdomen and remains completely concealed in the daytime.

Several females deposited eggs after copulation; but no larvæ were hatched. The odd shaped egg is shown in top and side view in figures $2, \mathrm{~d}$ and 2 , e.

Young galls found on Abutilon May 24, 1924 showed the first larval instar. The life history has thus been traced except the larval molts.

Meskea dyspteraria was described in 1877 by Grote in the Canadian Entomologist. A very brief and utilitarian life history is given by Heinrich in the Journal of Agricultural Research and his plates give only drawings of the head of the larvæ, the pupæ, and the arrangement of the larval setæ.

Some of the observations made in this paper are not new; but those describing the copulatory tuft in the male are, as far as I have been able to find, original and unique. I intend to make some further study of this species before discussing it in relation to other know phases of insect courtship.

In the photographic work on this paper I owe much to Reginald Painter, formerly tutor in Zoology at the University 
of Texas and now assistant in entomology at the University of Ohio.

\section{References.}

Grote, A. R. A new Species of Geometræ, Canadian Entomologist, Vol. 8, 1877, page 114 .

Heinrich, Carl. Some Lepidoptera likely to be Confused with the Pink Bollworm, Journal of Agricultural Research, Vol. 20, 1921, page 828 and plates 101, 104 and 109. 

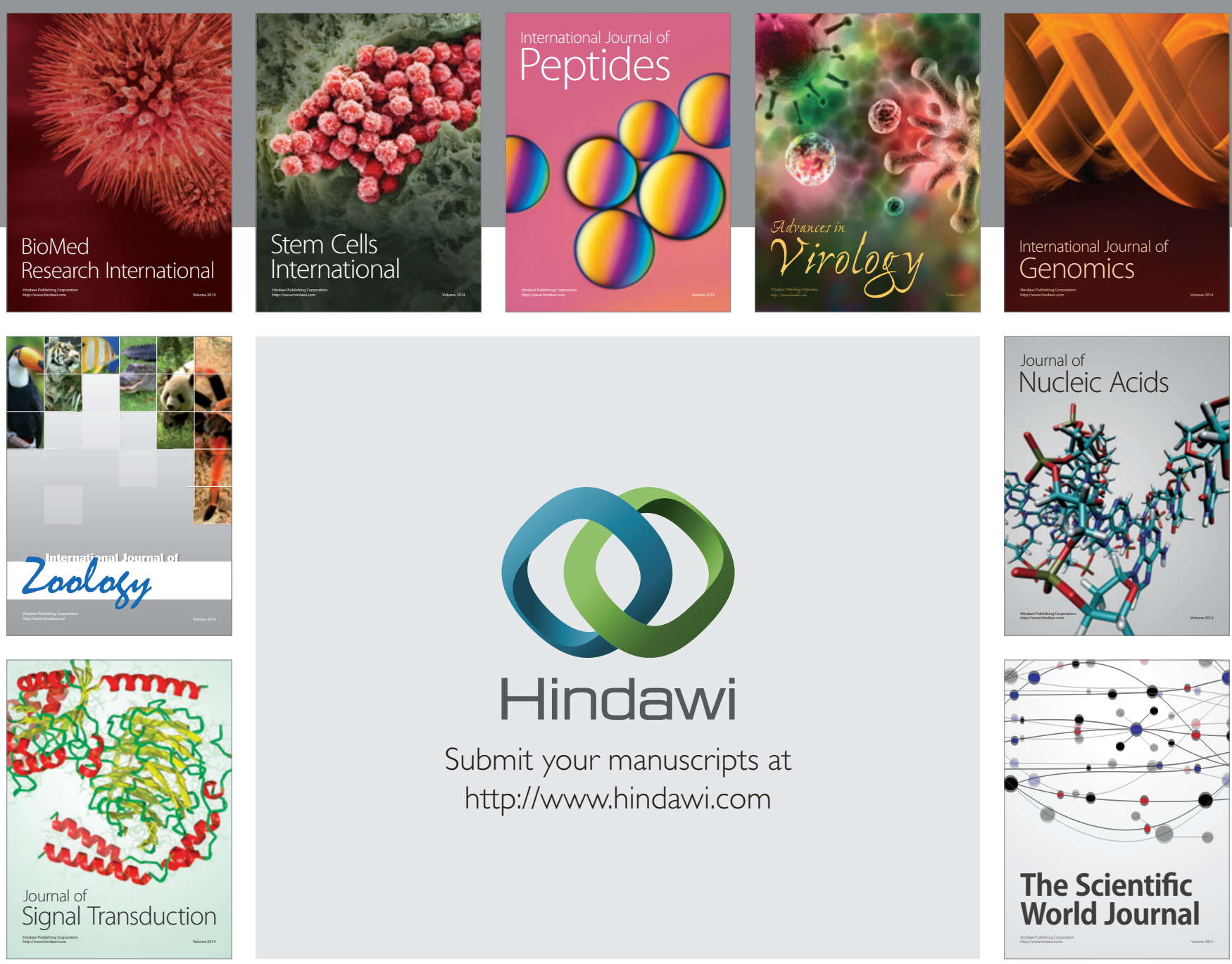

Submit your manuscripts at

http://www.hindawi.com
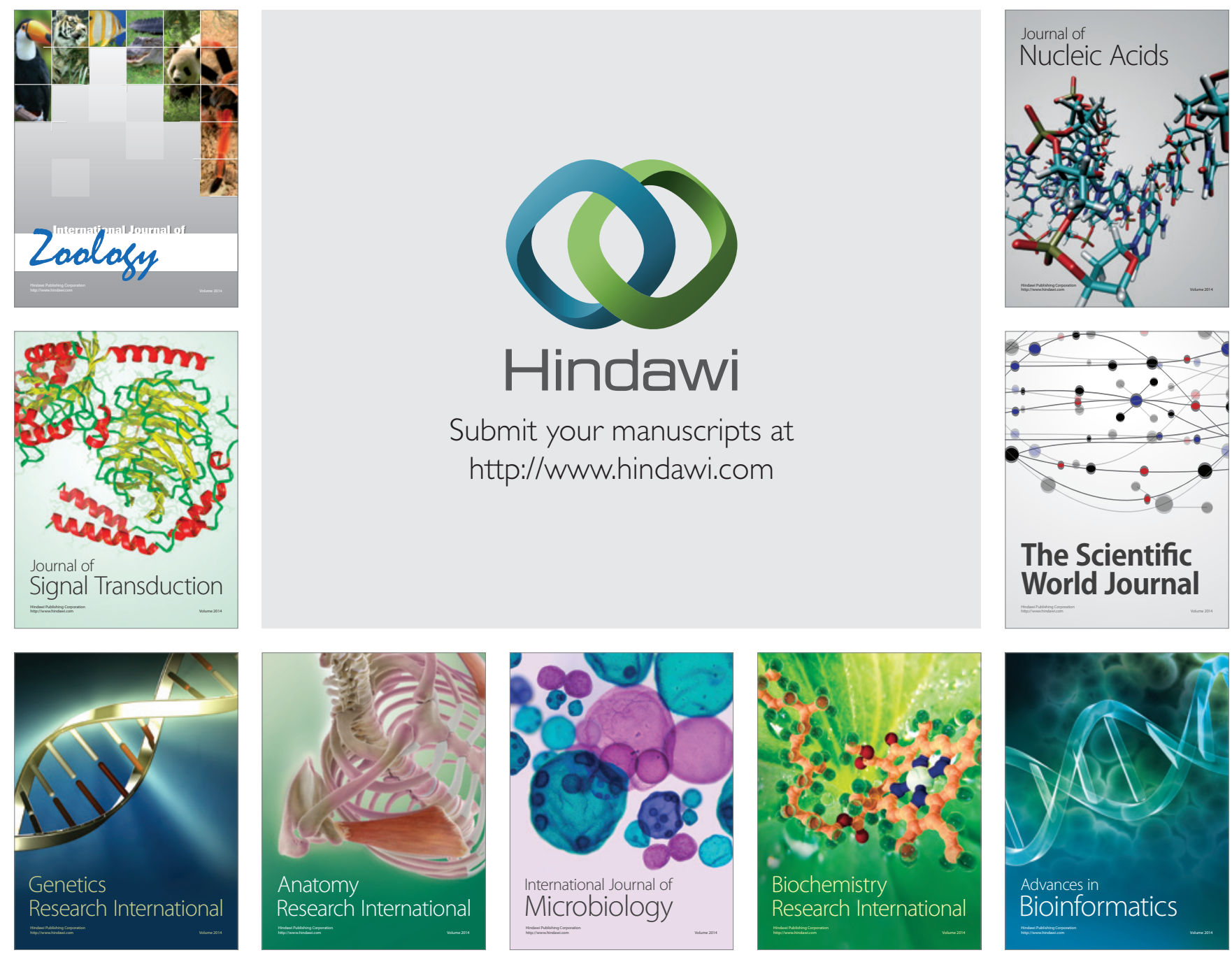

The Scientific World Journal
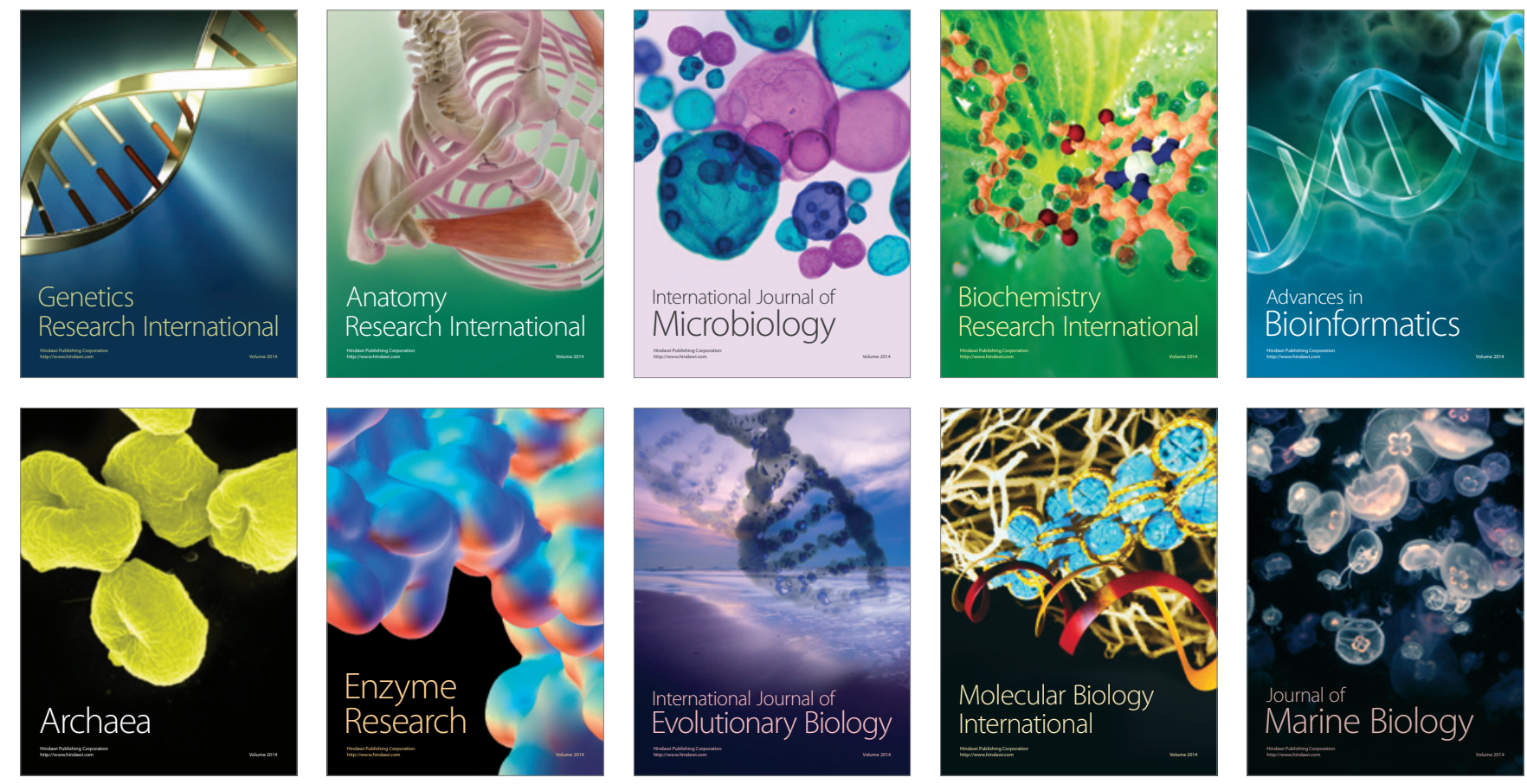